\title{
Analysis on the Status Quo of China's Advanced English Guide Test
}

\author{
Li Xiaonan \\ Hospitality department \\ Tianjin maritime college, TMC \\ Tianjin,China \\ E-mail:1ily2019151412@163.com
}

\begin{abstract}
With the gradual increase of inbound and domestic tourists as well as standards on tour guide market by Tourism Law, there has been an increasingly higher demand for advanced English guide in the market. The Test of Advanced English Tour Guide has been officially launched since 2011 after 15-year interruption; however, many new problems have occurred in the past four years. In this paper, the author explores and analyzes the existing problems in current test with proposal of some countermeasures.
\end{abstract}

Keywords-Advanced tour guide; English tour guide; examination of tour guide; status quo

\section{INTRODUCTION}

On October 1st, 2013, The Tourism Law of the PRC was officially implemented, which has made huge influence on tourism market especially on tour guides. According to the 41st article in the 4th chapter of the New Tourism Law, tour guides are forbidden to ask for tips from tourists, to induce, cheat, force or compel tourists to shopping or participate in some chargeable events in a disguised way[1]. Besides, their right to receive kickbacks from designated shopping stores is also canceled, which all leads to a shrinkage of tour guides' income. Thus, it has been a public concern that how travel agencies issue subsidies to tour guides to maintain and mobilize their activeness. According to the Instructive Opinions on Tour Guides' Basic Wages and Subsidy Standard issued by Jiaxing government in 2013, tour guides' subsidies can be determined by their levels. Besides, Under the guide of New Tourism Law, the 2nd term of Brief Report on Nanjing Tour Guides issued by Nanjing Tourism Association Branch on October 12, 2013 also disclosed together with National Standards on Tour Guides' Salaries in Other Tourist Cities that tour guides' subsidies should be determined by their level, which indicates that it is a necessary trend to connect tour guides' salaries to their guide ranks.

According to their technical levels, tour guides can be divided into four levels, that is, primary level, middle class, advanced level and special grade, during which evaluation on advanced and special tour guides was once interrupted in 1997. In order to further build the team of tour guides and improve the whole qualities and service level of tour guides, National Tourism Administration once took Zhejiang Province as a pilot place in 2010 by setting national grade examination for advanced tour guides. Among the 123 qualified candidates, only 62 passed the examination with the certificate of advanced tour guide of the PRC, within which there were only 7 qualifiers in the English team[2]. In April 2011, National Grade Test for
Advanced Tour Guides was officially implemented again after 15-year interruption[3], which was a reopening of selection for advanced tour guides as well as a national resolution to perfect tour guide system and improve tour guides' professional qualities.

\section{OVERVIEW ON THE TEST OF ADVANCED ENGLISH TOUR GUIDE}

Since the reopening in 2011, national grade test of advanced tour guides been held once a year in both Chinese and English. In this paper, the test of advanced English Tour Guide refers to the English test in National Grade Test of advanced tour guides. As for the requirements of advanced English tour guide test, inform of national grade test of advanced tour guide in 2014 and the examination outline in 2014 are taken as examples with detailed explanations.

\section{A. Registration conditions [4]}

1) Educational requirements:at least bachelor degree or

2) college degree majoring in tourism or foreign language.

3) Professional experience: with the acquisition of

4) middle-level tour guide certificate for over three years; at least have led tour groups for more than 90 days as the status of middle--level tour guide in the past three years.

5) Working performance: in the past three years, those

6) who were once deducted four points at one time (including four points) or 6 points in total in a year are not allowed to participate in grade test of advanced tour guide that year.

\section{B. Examination forms [5]}

The unified national written test is adopted by the test of advanced English tour guide. The examination outline is passed by national grade appraisal evaluation committee of tour guide and announced on the bulletin board of Chinese Tourism Online. Candidates for the examination can download the admission ticket independently.

There are no designated reference books for the examination, but it aims to test candidates' mastery and employment of tourism policies and rules, deep understanding of tourism development, mastery and analytic ability of major events home and abroad as well as comprehensive application of related tourism knowledge. 


\section{Subjects of examination and the contents [6]}

The test of advanced English tour guide has two subjects, which are comprehensive tourism knowledge and test on tour guides' capabilities. The examination questions are in English, and it also demands candidates to answer the questions in English.

The examination time of "comprehensive knowledge of tour guide" lasts 120 minutes, and the question types include gap filling, true or false questions, single selection and multiple-choice questions, within which there are 30 gap-filling questions with one point to each question, 20 true or false questions with one point to each question, 30 single-choice question with one point to question and 20 multiple-choice questions with one point to each question. The total score is 100 points.

This part mainly tests candidates' knowledge width and depth as well as their comprehensive mastery of tourism policies and legal rules and professional knowledge of related tourism legal policies, tourism business and tourism culture and so on.

The examination of "Test on Tour Guides' Capabilities" lasts 150 minutes. The examination types include analysis of tour cases and innovation of guide presentations. The case analysis includes two questions of dealing with tourist emergencies with 10 points to each question. It requires students to answer the two questions out from the given three questions. There are three questions of dealing with tourist disputes with 10 points to each question. It requires students to select three questions from the given four questions to make answers. As for the creation of guide presentation, it requires candidates to answer one of the given two questions with 50 points. The total score is 100 points.
In this part, it mainly tests candidates' capability of comprehensive employment of tourism policies and rules, management of tourism emergencies as well as treatment of tourism disputes. It requires tour guides to have deep analysis on various problems occurring in their tour trip with flexible treatment of emergencies; and meanwhile they should be capable of creating original and vivid guide presentations with high cultural connotation independently.

\section{ANALYSIS ON THE CURRENT SITUATION OF THE TEST OF ADVANCED ENGLISH TOUR GUIDE}

\section{A. Problems existing in the Test of Advanced English Guide}

According to statistics, by June 2013, the total amount of tour guides (with the possession of tour guide IC card) in China has reached 700 thousand, within which proportion of advanced English tour guides was less than $25 \%$, indicating a serious shortage of advanced English tour guides in our country. With the official recovery of the national test of advanced English guide, the amount of Chinese advanced English tour guides has increased gradually, but there are still some problems existing during the examination.

1) There have been less and less tour guides passing the test of advanced English tour guides.

The national test of advanced English tour guides has been reopened for four years, during which the passing rate has decreased gradually by the statistics (see figure 1). In 2012, 38 candidates passed the examination, but the number in 2013 and 2014 has reduced to 32 and 24 respectively.

Table I. Statistics of the People Who Passed the National Test of Advanced English Tour Guide

\begin{tabular}{|c|c|c|c|}
\hline Number of candidates/Year & In 2012 & In 2013 & In 2014 \\
\hline Number of qualified tour guides who pass the test & 38 & 32 & 24 \\
\hline
\end{tabular}

2) The number of people who register for the examination of advanced English tour guide has become smaller and smaller.

In the past years, people who registered for the test of advanced tour guide have become less and less, within which the number of people who participated in the test of advanced English tour guide has even been smaller. It is reported that there were only nine people participated in the test of advanced English tour guide in 2014, and three and one in Fujian and Tianjin respectively[7].

3) The passing rate of this examination is very low.

Since it has no designated reference books for candidates but testing their knowledge width and depth as well as comprehensive employment of tourist knowledge. Only several of the candidates could pass the test in various provinces. According to the statistics, there was only one candidate of the three in Fujian province passed the test in 2014; while the passing rate in Shanghai that year iwas zero.

\section{B. Analysis on the reasons}

1) Knowledge covered in the test of advanced English tour guide is wide and mixed.

There are no designated reference books for the test of advanced English tour guide by national rules, so the knowledge covered in the test is wide and mixed, including 16 policies and rules, regulations and orders, guiding suggestions and treating methods and so on. Besides, it also tests candidates' knowledge about development status of Chinese tourism, effect of major events home and abroad on tourism in recent years, basic tourism knowledge, and business knowledge of tour guide as well as treatment of tourist disputes. Thus, the examination becomes difficult with low passing rate for its extensive knowledge range.

2) Both English questions and English answers are required, which makes the test more difficult.

The test of advanced English tour guide becomes even more difficult for its English questions and English answers besides the wide and mixed knowledge range. 
Some candidates were already intermediate English guide, but they choose to register for advanced Chinese tour guide instead of advanced English tour guide, which reflects the difficulty in the test of advanced English tour guide. Meanwhile, candidates should also know about knowledge related to tourist destinations and tourist generating regions, which further increases the difficulty of test. Here is an example of multiple-choice question in the test of advanced English tour guide in 2014.

What movies were played by Audrey Hepburn?( )

A.My Fair Lady B.Gone with the Wind C.Roman Holiday D.Breakfast at Tiffany's E.War and Peace

The right answer of this question is ACDE. Such kind of question investigates candidates' related knowledge about tourist destinations and tourist generating regions, which can't be improved by short-term review but relies on candidates' daily study and accumulation.

3) Most tour guides are reluctant to take part in the grade test of tour guide with low activeness.

Although the market of tour guides has been standardized by the New Tourism Law with rethinking on the tour guides' salary system by traveling agencies, the New Tourism Law hasn't defined the direct relationship between tour guides' levels and tour guides' salaries. That is, the current tour guides' salary system indicates no differences in primary, intermediate and advanced tour guides. Therefore, most tour guides are reluctant to spend time or effort in the test. During the national grade test of advanced tour guide in 2013, candidates in Henan province submitted similar papers, thus all candidates' results were canceled by National Tourism Administration, which blew some candidates' activeness. And therefore there were fewer candidates in Henan province participating in the National Grade Test of Advanced Tour Guide in 2014.

\section{HOW TO PREPARE THE TEST OF ADVANCED ENGLISH TOUR GUIDE}

Although the test of advanced English tour guide is difficult, it is totally possible for candidates to pass the test based on scientific methods and collective review since most candidates are English tour guides of intermediate level with years of group-leading experience as well as certain knowledge reserve.

\section{A. Candidates can conduct comprehensive overview \\ by the requirements of examination outline \\ combined with self group-leading experience.}

In 2014, the examination outline of National Grade Test of Advanced Tour Guide included six parts of contents, which were tourism policies and rules, development situation of tourism, effect of major events on tourism, basic knowledge of tour guide, business knowledge of tour guide, treatment of tourist disputes. Although the contents seem to be mixed and complicated, they have been reviewed during the guide qualification examination and intermediate grade test for tour guide. In order to save time, candidates can review the knowledge by referring to papers in the past years.

\section{B. Candidates can collect major events related to} tourism in recent years by surfing on the Internet.

The test of advanced English tour guide also investigates candidates' concern about hot social topics such as the issuance of new laws and regulations, celebration of major activities as well as publication of annual ten tourism cases, etc. In the national test of advanced English tour guide in 2014, questions related to the newly implemented Tourism Law was once seen many times; besides, some questions were related to the FIFA World Cup Brazil. Therefore, candidates should keep an eye on the latest development of tourism with timely information about politics, national policies and global major tourism events by referring to the website of National Tourism Administration and Chinese Tourism Newspaper[9].

\section{Candidates should strengthen the review on English knowledge consciously.}

As for candidates participating in the test of advanced English tour guide, it is really important for them to possess qualified English level apart from knowledge reserve. Therefore, they should strengthen review on English knowledge in daily study. For example, they can refer to English materials directly by referring to designated reference books of test for intermediate English guide, such as Tour Guide Knowledge Specials and English. Besides, English version should be referred to about related rules and regulations. In addition, candidates are suggested to recite several beautiful essays of English tour guide presentations to cultivate their sense of language training.

\section{Candidates should face the examination with a sound mental state.}

It is also very essential to have a sound temporary performance during the examination besides abundant preparations before the test. How to give a normal play within limited time and under huge pressure depends on sound mental state. Candidates should face the examination calmly with a normal heart. When answering questions, candidates should also control time and speed flexibly. First, they should scan the paper quickly to know about questions so that they can have a best performance.

\section{REFERENCES}

[1] http://www.cnta.gov.cn

[2] Ren Ye. Restart of the Test of Advanced Tour Guide After 2014[N]. Chinese Tourism Journal, 2010-11-08 (the 009th term).

[3] Zhou Xinpeng. Things After the Reopening of National Grade Test of Advanced Tour Guide[N]. Chinese Tourism Journal, 2011-12-21(the 010th term).

[4] http://www.cnta.gov.cn

[5] http://www.cnta.gov.cn

[6] http://www.cnta.gov.cn

[7] http://www.tjlyrcw.com

[8] http://www.cnta.gov.cn/

[9] Guo Tao. To Arouse a Rational Development of Tourism by Demonstration of Advanced Tour Guides' Qualifications. [J] Journal of Yantai Vocational College, 2014(4):41-45. 